\title{
NASIONALISME ETNIS TIONGHOA DI KOTA BANDA ACEH
}

\author{
Irwan Putra ${ }^{1}$, Rusli Yusuf ${ }^{2}$, Sanusi ${ }^{3}$, Maimun ${ }^{4}$ \\ Program Studi PPkn Universitas Syiah Kuala, Indonesia \\ 1Email: irwanputra@unsyiah.ac.id \\ 2Email: rusliyusuft@unsyiah.ac.id \\ 3Email: sanusi@fkip.unsyiah.ac.id \\ 4Email: maimunaceh@unsyiah.ac.id
}

\begin{abstract}
ABSTRAK
Penelitian ini berusaha mengambarkan nasionalisme Etnis Tionghoa di Kota Banda Aceh, karena berkembang anggapan bahwa etnis tionghoa kurang memiliki rasa nasionalisme terlihat dari Bahasa, partisipasi, interaksi dan tanggung jawab mereka dalam masyarakat. Penelitian ini memakai kualitatif dengan metode studi kasus, untuk subjek penelitian sebanyak 20 orang, dilakukan dengan wawancara mendalam serta dianalisis melalui model interaktif, terdiri dari 4 jalur yaitu: pengumpulan data, reduksi data, penyajian data dan penarikan kesimpulan. Hasil penelitian, nasionalisme etnis tionghoa ternyata tinggi, walaupun banyak yang tidak mengikuti upacara bendera, dikarenakan sudah sepuh (tua). Kemudian mereka selalu mengibarkan bendera untuk menyemarkan kemerdekaan dan mengumpulkan sumbangan untuk memeriahkan acara kemerdekaan. Terkait tanggung jawab, etnis tionghoa memiliki komitmen tinggi menjaga kerukunan umat beragama (toleransi) dan memahami khasan Aceh (syariat islam), bahkan mereka aktif menjaga keamanan, karena ada stereotip (dicap) sebagai penyalahguna, bahkan penjual barang-barang terlarang (narkoba). Etnis tionghoa ternyata memiliki nasionalisme yang tinggi, tetapi nasionalisme tersebut sulit dilihat karena stereotip yang berkembang dalam masyarakat, sehingga partisipasi mereka tidak terlihat, bahkan bahasa sebagai budaya dan identitas sering disalahartikan sebagai ketidaknasionalisme-an mereka. Nasionalisme etnis tionghoa tidak dapat diukur dari apa yang terlihat, melainkan nasionalisme etnis tionghoa harus diterjemahkan sebagai perasaan dan keinginan mereka berada dan bersama-sama membangun serta menjaga Indonesia.
\end{abstract}

Kata Kunci: Nasionalisme; Etnis Tionghoa; Tanggung Jawab.

\section{ABSTRACT}

This research tries to describe the nationalism of the Chinese ethnic in Banda Aceh, because there is a growing assumption that ethnic Chinese lack a sense of nationalism seen from their language, participation, interaction and responsibility in society. This research used a case study method, for the research subjects as many as 20 people, conducted by indepth interviews and analyzed through an interactive model, consisting of 4 paths, namely: data, data reduction, data presentation and data collection. The result of the research, ethnicity nationalism, although many do not follow the flag ceremony, because they are old (old). Then they always raise the flag to promote independence and collect donations to celebrate independence events. Regarding responsibility, Chinese ethnicity has a high commitment to maintaining religious harmony (tolerance) and understanding the specialties of Aceh (Islamic law), they are even active in maintaining security, because there are stereotypes (labeled) as abusers, even sellers of illegal goods (drugs). Chinese ethnicity turns out to have high nationalism, but nationalism is difficult to see because of the stereotypes that develop in society, so that their participation is not visible, even language as culture and identity is often misinterpreted as their nationalism. Chinese ethnic nationalism cannot be measured from what is seen, but Chinese ethnic nationalism must be translated as their feelings and desires to exist and jointly develop and protect Indonesia.

Keywords: Nationalism; Ethnic Chinese; Responsible. 


\section{PENDAHULUAN}

Keberagaman budaya dan etnis yang mendiami gugusan kepulauan Indonesia merupakan karunia Tuhan harus disyukuri dan dijaga agar menumbuhkan kebanggaan dan membangkitkan nasionalisme warga negara Indonesia. Tetapi nasionalisme Indonesia selalu menjadi diskursus yang menarik untuk dijadikan lokus. Karena nasionalisme untuk negara Indonesia sangat dibutuhkan untuk dapat merawat dan menjaga keutuhan bangsa (Chairul Anwar, 2014).

Salah satu tema nasionalisme yang menghangat diperbincangkan ialah nasionalisme Etnis Tionghoa, walaupun sudah sejak berabad-abad lalu Etnis Tionghoa telah berbaur dan mendiami Indonesia. Sejak ekspedisi Laksamana Cheng Ho kewilayah sumatera dan nusantara (Kong, 2005).

Berdasarkan hasil penelusuran peneliti setidaknya ada dua alasan mengapa nasionalisme Etnis Tionghoa dipertanyakan. Pertama, karena banyak stereotip yang menyatakan bahwa Etnis Tionghoa adalah orang asing, sehingga rasa nasionalismenya terhadap Indonesia perlu dipertanyakan (Hapsari, 2016). Kedua, ada stigma bahwa Etnis Tionghoa merupakan economic animal yang tidak memiliki loyalitas politik, nasionalis dan hanya mementingkan diri sendiri. Etnis tionghoa memiliki dualisme nasionalisme di dalam kelompok atau etnis mereka, adanya yang memihak kepada negeri China, adanya tetap setia kepada Belanda, tetapi ada pula yang memihak ke Indonesia (Hapsari, 2016).

Banyak stereotif dan sentimen yang berkembang dimasyarakat, akhirnya juga turut berpengaruh terhadap pandangan sebagian masyarakat Aceh terhadap nasionalisme Etnis Tionghoa di Aceh. Sehingga turut dipengaruhi pandangan dari masyarakat Aceh bahwa etnis tionghoa tidak mendapat tekanan atau gangguan (aman) dari Gerakan Aceh Merdeka (GAM). Kondisi tentu berbeda dengan etnis lainnya yang menetap di Aceh. Konflik bersenjata mengakibatkan masyarakat sipil (korban) di Aceh mengalami teror, intimidasi dan diusir dari desa-desa tempat tinggal, bahkan banyak yang meninggal dunia ketika konflik (Ketaren \& Nasution, 2018).

Kemudian berdasarkan hasil observasi, hangatnya isu penistaan agama dan serangkaian gelombang unjuk rasa (aksi damai) $212 \mathrm{di}$ Jakarta ikut mempengaruhi persepsi masyarakat Indonesia terhadap etnis tionghoa. Rangkaian kasus dan peristiwa diatas ikut mempenagruhi pandangan dan persepsi masyarakat Aceh terhadap rasa nasionalisme Etnis Tionghoa yang berada di Kota Banda Aceh. Penelitian ini penting dilakukan, mengingat daerah Aceh merupakan daerah yang baru selesai dari konflik dan rawan serta mudah provokasi dari isu-isu yang tidak bertanggung jawab.

Walaupun dalam beberapa kajian terhadap nasionalisme Etnis Tionghoa di Indonesia, menerangkan dan menjelaskan bahwa mereka memiliki nasionalisme yang tinggi terhadap Indonesia. Ini dituturkan Darini (2008) ketika awal kemerdekaan, Partai Tionghoa Indonesia telah mengidentifikasikan diri sebagai Warga Negara Indonesia (WNI) yang memiliki kepedulian tinggi, berjuang bersama untuk memperjuangkan nasionalisme dan kemerdekaan Indonesia.

Suryadinata (2010) ikut menegaskan bahwa Etnis Tionghoa pada masa Orde Baru dipaksakan untuk mengasimilasikan identitas dengan budaya Indonesia, pada hal identitas merupakan cara atau tanda pengenal untuk mendefinisikan siapa diri kita, berarti secara tidak langsung Etnis Tionghoa dipaksa memiliki nasionalisme ke-Indonesia-an. Sedangkan nasionalisme tidak terlepas dari makna perasaan dan keinginan untuk bersama. Menurut Kohn (1984) nasionalisme merupakan loyalitas dan komitmen tertinggi kepada negara kebangsaan serta merupakan faktor hakiki dalam pembentukan suatu bangsa atau negara. Nasionalisme dalam pandangan 
para ahli Indonesia merupakan paham kebangsaan dalam bentuk kesadaran diri yang meningkat berwujud kecintaan atau loyalitas bangsa, negara dan kebudayaan yang merupakan kekuatan bangsa.

Secara lebih luas definisi nasionalisme dapat dilihat dari pernayataan Druckman (1994), beliau mengemukakan nasionalisme mengarah pada kesetiaan tertinggi individu terhadap bangsa dan tanah airnya dengan menghargai dan mencintai bangsanya. Di lain pihak Bradat (1993:41) berupaya mempertegas definisinya nasionalisme sebagai nation state, bahwa:

\section{Nationalisme is the theory of the nation state, and as such it has had an enormous impact on the modern world...nation is a sosiological term referring to a group of people who have a sense of union with one another. State is a political term that includes four element: people, territory, government, and sovereignty...yet, several theories of the origin of the state have had an impact on ntionalism as ideology.}

Berdasarkan pandangan tersebut nasionalisme dapat diartikan sebagai teori dari negara bangsa, dan rasa kecintaan terdapat negara serta terikat secara politik dan ideologi. Sedangkan untuk konteks Indonesia saat ini, nasionalismenya merupakan hasil perjuangan bersama dan perasaan untuk bersama-sama mewujudkan Indonesia yang maju dan sejahtera. Nasionalisme sebagai ideologi memerlukan aktualisasi sesuai dengan konteks perubahan zaman dan tantangan yang dihadapi bangsanya (Anggraeni Kusumawardani \& Faturochman 2004). Kedua hal inilah yang terus mempengaruhi eksistensi Nasionalisme Indonesia baik dilihat dari aspek definisi dan praksisnya.

Kemudian melihat dan mencermati isu-isu kontemporer saat ini, kebangkitan etnisitas dalam negara dan bangsa menjadi tantangan yang sulit untuk dihindari. Indonesia sebagai sebuah negara bangsa sedang alami hal ini. Suryadinata (2010) mengemukakan bahwa sedang terjadi kebangkitan kebudayaan salah satunya kebangkitan kebudayaan Etnis Tionghoa di Indonesia. Hal yang sama juga diidentifikasi oleh Gungwu (1988:9), beliau mengungkapkan bahwa ada tujuh identitas Etnis Tionghoa dan salah satunya identitas nasionalis China yang berkaitan dengan orientasi sebagian kelompok Etnis Tionghoa terhadap nasionalisme di China.

Kebangkitan identitas China tersebut dapat dalam dua paradigma yaitu: Pertama kebangkitan tersebut merupakan cara untuk mempertahankan kebudayaan mereka dalam rangka eksistensi diri; Kedua kebangkitan tersebut sebagai bagian dari politik identitas yang dapat mengancam keutuhan dan persatuan Negara Kesatuan Republik Indonesia (NKRI). Walaupun sebagaian besar dari Etnis Tionghoa telah menyesuaikan diri dengan kebudayaan dan identitas keindonesiaan. Misalnya di Provinsi Aceh, tetapi Etnis Tionghoa tetap mempertahankan identitas historis dan budaya leluhur mereka (Usman, 2009).

Melihat beberapa permasalahan yang telah dikemukakan, peneliti tertarik melihat dan menganalisis nasionalisme Etnis Tionghoa di Kota Banda Aceh berdasarkan sikap dan prilaku nasionalisme, yakni: (1) Cinta terhadap tanah air dan bangsa (2) Berpartisipasi dan tanggung jawab Etnis Tionghoa.

\section{METODE}

Penelitian ini mengunakan pendekatan kualitatif dengan metode studi kasus. Studi kasusadalah salah satumetode penelitian yang digunakan ilmu-ilmu sosial (Yin 2014 Smith dalam Denzin dan Lincoln; 2009). Melalui metode ini peneliti dapat merumuskan dan menentukan subjek penelitian agar dapat 
memperoleh informasi dan data yang akurat berdasarkan kriteria, latar setting, actors, events dan process (Miles dan Huberman, 1992; Alwasilah, 2003).

Terkait menentukan informan, peneliti mengunakan Purposive sampling dan snowball sampling, untuk mendapatkan informan yang berkualitas dan mampu memberikan penjelasan dan menjawab yang berkualitas terkait masalah penelitian. Jumlah responden penelitian ini berjumlah sebanyak 20 orang responden. Teknik pengumpulan data yang dilakukan berupa 1) in depth interview, dilakukan melalui tanya jawab oleh peneliti dengan informan; 2) participant observation, dilakukan untuk melengkapi hasil wawancara; 3) study of documents mengumpulkan literature dan dokumen pendukung penelitian. Penelitian ini mengunakan metode analisis model interaktif dengan 4 alur tahapan, yaitu 1) Pengumpulan Data; Reduksi Data; Penyajian Data; dan Penarikan Kesimpulan (Miles \& Huberman, 1992).

\section{HASIL DAN PEMBAHASAN Perasaan Cinta terhadap tanah air}

Berdasarkan hasil wawancara di lakukan secara mendalam dengan informan terhadap rasa nasionalisme, peneliti hanya memunculkan beberapa pertanyaan yang dapat mewakili untuk menggambarkan kondisi atau keadaan nasionalisme dalam hasil penelitian ini. Ketika ditanyakan perihal partisipasi mereka dalam memeriahkan hari kemerdekaan, secara spontan beberapa informan menyampaikan bahwa masyarakat atau etnis tionghoa sebagian besar ikut bersamasama dengan masyarakat kota banda aceh berpartisipasi dalam merayakan kemerdekaan, walaupun tidak memperlihatkan secara terang-terangan, seperti ikut upacara, pawai dan bentuk kegiatan lainnya.

Sedangkan untuk mengibarkan bendera mereka selalu mengibarkan bendera, tetapi mereka menyadari bahwa kondisi tempat tinggal mereka yang berada di belakang areal pertokoan dan gang sempit di dalam kawasan daerah Peunayoung sehingga mungkin tidak dapat terlihat jelas oleh masyarakat umum, karena tidak semua masyarakat berkepentingan mengunjungi daerah tempat tinggal mereka. Kemudian informan juga menyatakan bahwa tokotoko tempat perniagaan mereka juga mengibarkan bendera dan umbul-umbul, tetapi karena mereka tidak bekerja menjaga toko-toko (melayani pedagang), sehingga banyak orang yang berangapan toko miliki orang aceh, bukan orang etnis tionghoa.

Selanjutnya terkait dengan upacara bendera, mereka mengakui bahwa memang banyak diantara mereka yang tidak ikut dalam upacara bendera, bukan karena tidak suka atau tidak nasionalis tetapi karena kondisi fisik mereka yang kebanyakan sudah tua, sedangkan anak-anak (generasi muda) mereka telah banyak yang merantau untuk berdagang dan sekolah di luar daerah, jikapun ada Banda Aceh sebagaian besar sibuk mengurus anak-anak. Mereka juga mengungkapkan di sekolah-sekolah anakanak dan cucu-cucu mereka mengikuti pawai, sehingga orang tua atau generasi muda sibuk mencari baju adat nasional untuk memeriahkan hari kemerdekaan tersebut. Bahkan organisasi perhimpunan etnis tionghoa di Banda Aceh juga ikut upacara dan mempertunjukan atraksi barongsai.

Berdasarkan pernyataan tersebut dapat disimpulkan bahwa rasa nasionalisme atau kecintaan terhadap Indonesia yang tumbuh dan berkembang dalam diri etnis tionghoa tidak bukan hanya ditunjukan melalui atau mengadiri upacara bendera tetapi lebih pada perbuatan dan memaknai upacara kemerdekaan sebagai wadah untuk menghargai perjuangan dan pengorbanan para pahlawan.

Nasionalisme masyarakat Tionghoa dapat sebenarnya tinggi, karena mereka aktif berpartisipasi dalam mengibarkan Bendera Merah Putih didepan rumah, taat 
aturan, membayar pajak, Dll. Harus diakui bahwa perasaan nasionalisme di Indonesia, bahkan di dunia selalu dilihat atau dibuktikan dari partisipasi yang bersifat terbuka (dapat dilihat) seperti mengikuti Upacara Bendera, Pawai, menyanyikan lagu Indonesia Raya. Pada dasarnya konsep Nasionalisme dipandang sebagai ideologi (Eriksen, 1993; Smith 2003 Singgih, 2018), ideologi mengutamakan kesadaran warga negara akan pentingnya bangsa dan negaranya, untuk itu konsep nasionalisme harus ditanamkan lewat kesadaran bukan pemaksaan.

Kecintaan atau nasionalisme Etnis Tionghoa terhadap Indonesia ditunjukan dengan beberapa pernyataan yang mempertegas bahwa mereka tidak menyetujui jika Provinsi Aceh memisahkan diri dari NKRI, karena mereka menganggap Daerah Aceh merupakan modal pembentukan Indonesia dan akan maju jika terus bersama dengan Indonesia.

Kemudian mereka menyampaikan beberapa poin-poin penting terkait alasan etnis tionghoa mencintai Indonesia ialah:

1) Kami lahir di Aceh walaupun bukan suku asli tetapi kami mencintai Indonesia dan Aceh adalah bagian dari Indonesia.

2) Indonesia adalah sebuah negara yang lahir dari perjuangan dan juga kontribusi nenek moyang kami, maka kami mencintai Indonesia.

3) Walaupun kami etnis tionghoa tetapi kami tidak mencintai Pemerintahan China, yang kami cintai ialah kebudayaannya karena budaya leluhur berkaitan dengan nilai-nilai spiritual atau agama yang kami anut.

4) Perasaan bangga sebagai warga negara Indonesia walapun Indonesia memiliki banyak permasalahan karena kami dilahirkan disini (AcehIndonesia).

5) Banda Aceh (Indonesia) merupakan tempat kehidupan (ekonomi), dan juga sebagai tempat kami meninggal, maka sudah sepantasnya kami mencintai Indonesia.

Beberapa pernyataan diatas menunjukan rasa nasionalisme etnis tionghoa terhadap indonesia, walaupun mereka selalu dianggap dan diindentikan tidak nasionalis bahkan komunis tetapi mereka memiliki nasionalisme yang tinggi. Rasa nasionalisme etnis tionghoa sudah masuk pada taraf kesadaran akan persatuan bangsa dan kemerdekaan. Kesadaran terhadap nasionalisme etnis tionghoa banyak dipengaruhi factor structural, dimana faktor ini lebih didasarkan pada pertimbangan rasional (Tatang, dkk., 2006). Perasaan senasib dan sepenanggungan ternyata mampu mengalahkan perbedaan etnik, budaya, dan agama sehingga lahir nasionalisme keindonesian (Umi, dkk 2018).

Bersadarkan rekam sejarah perjalan bangsa, pemberontakan, sparatisme Dll. di indonesia merupakan ketidakpuasaan terhadap keadilan, kesejahteraan dan kesamaan. Effendi (1995) menyatakan alasan sebagian besar etnik ingin memisahkan diri dari negara induk, antara lain karena ketidakadilan dan perasaan tertekan terus menerus dan diperlakukan sebagai warga negara kelas dua. Karena saat ini nasionalisme berkaitan erat dengan masalah state building dan mengacu pada agregasi individu dan kelompok yang dikaitkan dengan tempat dan karakteristik yang sama. (Calhoun, 1993).

Maka dengan demikian rasa kebangsaan dan sikap nasionalisme yang dimiliki oleh Etnis Tionghoa harus tetap dijaga dan dipupuk agar dapat tercapainya keaslian dan harga diri. Jangan sampai kita terjebak pada nasionalisme yang sempit dimana kita hanya memaknai nasionalisme dalam kesamaan budaya, tindakan dan bahasa. Karena konsep nasionalisme Indonesia terletak pada perasaan kebangsaan yang berpijak pada kondisi masyarakat yang multicultural dan multietnis, serta politik. Sehingga dengan 
konsep kebangsaan itulah negara menjamin hak-hak politik dalam entitas (suku,bangsa) untuk tumbuh dan berkembang serta menyatu dalam keindonesiaan.

Ukuran nasionalisme sangatlah luas, baik secara definisi, konsep, mau pun persepsi ahli. Untuk itu perasaan nasionalisme etnis atau masyarakat tionghoa tidak dapat hanya dilihat dari apa yang terlihat (tampak), tetapi nasionalisme tionghoa harus diterjemahkan sebagai keinginan mereka berada dan bersamasama membangun serta menjaga negara Indonesia. Nasionalisme adalah paham yang unik, Keunikan dari nasionalisme tergambar dari ketotalitasan (Mifdal Zusron Alfaqi, 2016). Paham unik dan ketotalitasan dalam konteks etnis tinghoa dapat diartikan ialah cara pandang yang berbeda dimana nasionalisme tidak harus ditujukan untuk merendahkan orang dan bangsa lain. Namun nasionalisme merupakan perasaan yang tumbuh karena kesadaran dan keinginan untuk terus bersama-sama mewujudkan tujuan NKRI.

\section{Berpartisipasi dan tanggung jawab etnis tionghoa.}

Kemudian dalam sesi wawancara mendalam selanjutnya tentang pengunaan bahasa China dalam interaksi antar warga dalam kelompok, beberapa informan menyatakan bahwa pengunaan bahasa etnis atau asli china bukan karena mereka tidak mencintai indonesia tetapi karena bahasa china membuat keterikanan sosial dan hubungan emosional menjadi semakin erat antar mereka.

Beberapa informan mengungkapkan bahwa pengunaan Bahasa China oleh Etnis Tionghoa sama halnya dengan pengunaan bahasa masing-masing oleh suku Aceh dan suku Gayo, dan suku lainnya di Provinsi Aceh. Di Kota Banda Aceh memang hampir seluruh kegiatan yang dilakukan antara semasa suku mengunakan bahasa suku mereka, sama halnya dengan etnis tinghoa. Terkait hal ini banyak informan menyatakan, sebenarnya pengunaan bahasa apapun tidak menjadi masalah selama memudahkan komunikasi, hanya saja ada sebahagian kalangan mempertanyakan bahasa karena tidak suka melihat etnis tinghoa lebih maju dalam bidang ekonomi khususnya perdagangan.

Selanjutnya ketika ditanyakan perbandingan rasa kecintaan terhadap China dan Indonesia, beberapa informan menjawab lebih diplomatis, dengan mengungkapkan bahwa kecintaan mereka terhadap China karena tradisi, budaya dan tanah leluruh. Sementara kecintaan mereka terhadap Indonesia karena Indonesia adalah tempat lahir, hidup dan mati, maka kecintaan mereka terhadap indonesia lebih tinggi dari pada China.

Terkait sikap berpartisipasi masyarakat etnis tinghoa dalam pembangunan, hampir semua masyarakat berpartisipasi. Ketika ditanya pembayaran pajak, semua informan menyatakan bahwa mereka selalu membayar pajak, karena membayar pajak merupakan bagian atau upaya membangunan yang akan kembali pada mereka. Walaupun sebagain dari mereka menyatakan ada yang telat karena ekonomi tidak selalu stabil. Kemudian ketika ditanyakan tentang partisipasi mempertahankan Indonesia saat konflik, banyak informan menyatakan bahwa kondisi mereka pada saat itu serba sulit karena mereka merupakan minoritas apalagi setelah krisis dan kerusuhan pada tahun 1998 sehingga mereka tidak boleh secara terang-terangan mendukung pemerintah.

Kemudian ditanyakan tentang bertanggung jawab dengan menghargai orang lain melalui pertanyaan toleransi antar umat beragama, sebagaian besar informan mengungkapkan bahwa mereka sangat toleran terhadap pemeluk agama khususnya islam di aceh karena mereka meyakini agama merupakan nilai-nilai kebaikan sehingga tidak perlu dipertentangkan. Karena nasionalisme 
Indonesia bersemayam dalam keadilan sosial yang menekankan pada hak-hak dasar penghormatan, penghargaan, keadilan dan toleransi antarmanusia (Kartodirdjo, 1999).

Masyarakat Tionghoa di Banda Aceh mengunakan bahasa tionghoa dalam keseharian mereka ketika mereka berkomunikasi dengan sesama etnis tionghoa, untuk meningkatkan keakraban dan rasa memiliki budaya, karena budaya merupakan jati diri seseorang tidak dapat di hapuskan, bahkan entitas atau identitas seseorang atau kelompok masyarakat harus terus dirawat dan dijaga untuk menumbuhkan dan mengukuhkan pengakuan terhadap keberadaan mereka sebagai sebuah masyarakat, etnis atau suku yang bersama-sama membangun negara Indonesia.

Walaupun bahasa Indonesia diakui sebagai bahasa resmi negara dan bahasa pemersatu indonesia. Bahasa Indonesia sangat penting peranannya sebagai alat komunikasi, alat perjuangan dalam menumbuhkan, menggerakkan semangat kebangsaan (nasionalisme) (Ni Nyoman; 2018). Tetapi pengunaan bahasa China bagi masyarakat tionghoa terkait dengan spiritualitas, dimana ada istilah atau hal-hal yang tidak dapat diistilahkan dengan bahasa Indonesia dan lebih tepat jika mengunakan bahasa mereka, hal tersebut sama seperti sebahagian besar masyarakat indonesia yang mengunakan bahasa daerahnya.

Sudah seharusnya identitas dalam kebudayaan yang beragam membuat kita bangga dan nasionalis. Dengan nasionalisme suatu negara-bangsa akan memiliki kekuatan, semangat, dorongan dan kegigihan untuk mempertahankan bangsa dan negaranya bahkan sebagai pengenal (identitas nasional) (Anderson, 1991:6). Maka identitas nasional Indonesia ialah hasil kesepakat seluruh suku bangsa yang ada di bumi nusantara-Indonesia.

Hanya terkadang ketika etnis tinghoa mengunakan bahasa mereka ada pandangan stereotif terhadap mereka, sehingga sering dikatakan atau dikaitkan dengan ketidak nasionalisme mereka. Padahal pengunaan Bahasa China atau Tionghoa merupakan untuk meneguhkan identitas dan keberagaman Indonesia. Maka pandanganpandangan streotif terhadap etnis tinghoa harus dihapuskan atau mulai dihilangkan mengingat tantangan yang dihadapi oleh bangsa Indonesia dalam mempertahankan persatuan dan kemerdekaan menuntut adanya identitas dan harga diri sebagai sebuah bangsa atau nasionalisme yang seutuhnya.

Menurut Hans Konh (dalam Mertodipuro, 1984:11) menyatakan:

Nasionalisme ialah paham tentang kesetiaan tertinggi dari individuyang diserahkan kepada negara-kebangsaan. Perasaan ini sangat karena berikatan erat dengan tanah kelahiran, tradisitradisi dan penguasa-penguasa di daerahnya.

Secara lebih khusus Anthony D. Smith dalam Frans Kowa (2003) mengungkapkan bahwa makna nasionalisme adalah kesadaran memiliki bangsa bersangkutan. Kesadaran memiliki bangsa Indonesia sebagai tanah air dan negara serta pandangan bahwa loyalitas justru lebih penting daripada sekedar mempermasalahkan pengunaan bahasa dan asal usul bangsa. Seharusnya kesadaran akan nasionalisme pada masyarakat tionghoa harus terus di pupuk dan dijaga demi terwujudnya NKRI. Karena nasionalisme merupakan rasa kebangsaan, yang lahir berdasarkan kesadaran diri yang meningkat dari waktu-kewaktu yang berwujud kecintaan pada tanah air dan bangsa sendiri (Poerwadarminta, Dkk. 1987).

Walaupun dalam beberapa kasus dalam negara modern adanya dominasi dari negara (nasionalisme) terhadap etnis maka dengan sendirinya perlahan etnisitas itu akan kurang berkembang atau tidak 
eksis. Tetapi jika rasa nasionalisme dan etnis itu dibiarkan beriringan dan tidak diarahkan untuk saling memusuhi atau mendominasi (kanibal) maka etnisitas dapat mendukung nasionalisme karena Indonesia ialah negara kebangsaan dimana semua suku, etnis dan bangsa bersatu membangun negara Indonesia. Untuk itu, perlu dipersiapkan langkah-langkah strategis untuk mendukung upaya menjaga nasionalisme dan kepercayaan setiap suku bangsa terhadap negara, karena nasionalisme kesetiaan dalam bentuk kepercayaan atas harapan atau tujuan yang dicita-cita bersama-sama.

Tentu negara mempunyai tugas dan tanggung jawab. Maka Black menyatakan bahwa negara merupakan sekumpulan orang yang menempati suatu wilayah, diikat oleh ketentuan-ketentuan hukum yang disepakati dan diawasi oleh pemerintah dan masyarakat (Sollitan, Posumah, \& Rengkung, 2020). Untuk itu idealnya, semakin majunya sebuah negara harusnya diikuti juga semakin tumbuh dan kuatnya semangat nasionalisme, sehingga nasionalisme bukan hanya menjadi kata tetapi sebuah makna yang hidup dalam pikiran dan tindakan warga negaranya.

\section{SIMPULAN}

Berdasarkan hasil penelitian dapat disimpulan bahwa nasionalisme etnis tionghoa dapat dikatakan tinggi hal ini terungkap berdasarkan data wawancara yang dikumpulkan. Nasionalisme etnis tionghoa ini tergambarkan mulai dari aktif berpartisipasi mereka dalam mengibarkan bendera merah putih, taat membayar pajak dan ikut upacara dan berpartisipasi. Selanjutnya pada aspek tanggung jawab, para etnis tionghoa memiliki toleransi antar umat beragama yang tinggi. Tingginya nasionalisme etnis tionghoa tidak terlepas dari kondisi lingkungan masyarakat aceh yang mendukung untuk perekonomian dan tempat yang toleransi. Kemudian perasaan nasionalisme masyarakat tionghoa tidak dapat hanya dilihat dari apa yang terlihat (tampak), tetapi nasionalisme tionghoa harus diterjemahkan sebagai keinginan mereka berada dan bersamasama membangun serta menjaga negara Indonesia.

\section{DAFTAR PUSTAKA}

Alwasilah, A. Chaedar. (2015). Pokoknya Studi Kasus, Pendekatan Kualitatif. Bandung: PT Kiblat Buku Utama

Darini, R. (2008). Nasionalisme Etnis Tionghoa di Indonesia 1900-1945. Jurnal Mozaik Ilmu Sosial Dan Humaniora, 4, 1-12

Denzin, N. K., \& Lincoln, Y. S. (2009). Handbook of Qualitative Research, terjemahan Dariyatno, at. all. Yogyakarta: Pustaka Pelajar.

Druckman, D. (2001). Negotiation and identity: Implications for negotiation theory. International Negotiation, 6(2), 281-291.

Hans Kohn, (1984), Nasionalisme Arti dan Sejarahnya, Terj. Sumantri Mertodipuro. Jakarta: Erlangga.

Hapsari, R. D. (2016). Bibit Nasionalisme di Kalangan Penduduk Tionghoa di Indonesia. Jurnal Politica Dinamika Masalah Politik Dalam Negeri Dan Hubungan Internasional, 7(2), 255270.

Ketaren, A., \& Nasution, P. P. P. A. (2018). Konflik Gam-Ri Dan Kerentanan Pangan Masyarakat Transmigran. Jurnal Antropologi: Isu-Isu Sosial Budaya, 20(1), 103. https://doi. org/10.25077/jantro.v20.n1.p103117.2018

Kong, Y. (2005). Silang Budaya TiongkokIndonesia. Jakarta: Bhuana Ilmu Populer.

Kusumawardani, A., \& Faturochman, M. A. (2004). Nasionalisme. Buletin Psikologi, 12(2).

Maimun, M., Sanusi, S., Rusli, Y., \& Muthia, 
H. (2020). Internalisasi Nilai-nilai Karakter Kebangsaan Melalui Literasi Budaya dan Kewarganegaraan di Sekolah Menengah Atas (SMA) Kota Banda Aceh. CIVICUS: PendidikanPenelitian-Pengabdian Pendidikan Pancasila dan Kewarganegaraan, 8(1), 8-15.

Smith, Anthony D. (2003). Nasionalisme, Teori, Ideologi, Sejarah. Jakarta: Penerbit Erlangga

Usman, A. Rani, (2009). Etnis Cina Perantauan di Aceh, Yayasan Obor Indonesia, Jakarta.

Yusuf, R., Sanusi, S., Razali, R., Maimun, M., Putra, I., \& Fajri, I. (2020). Tinjauan literasi budaya dan kewargaan siswa SMA se-Kota Banda Aceh. Jurnal PendidikanKewarganegaraan Undiksha, 8(2), 91-99.

Mifdal Zusron Alfaqi (2016) melihat sejarah nasionalisme indonesia untuk memupuk sikap kebangsaan generasi muda. Jurnal Civics Volume 13 Nomor 2, Desember 2016

Bradat, Leon P.(1993). Political Ideologies: Their Original and Impact, Fifth Edition, Englewood Cliffs. New Jersey: Prentice Hall.

Suryadinata (2010). Etnis Tionghoa dan Nasionalisme Indonesia, Sebuah Bunga Rampai 1965-2008, Kompas Media Nusantara, Jakarta.

Gungwu, Wang, (1988). The Study of Chinese Identities in Southeast Asia dalam Changing Identities of The Southeast Asian Chinese since World War II, Editor Jennifer Cushman dan Wang Gungwu, Hong Kong University Press, Hong Kong.Kohn, Hans. 1955. Nasionalisme: arti dan sejarah. Terjemahan oleh Sumantri Mertodipuro. 1984. Jakarta: Erlangga. Ni Nyoman Kertiasih bahasa indonesia dan nasionalisme di indonesia Vol. 2, No. 2, Juli2018, 187-192 Available Online at https://ejournal.warmadewa.ac.id/ index.php/kulturistik DOI: dx.doi. org/10.22225/kulturistik.2.2.808

Anderson, Benedict, Imagined Communities. Reflections on the Origins and the Spread of Nationalism, 2nd edition (London: Verso, 1991 [1983])

Calhoun, Craig, Nationalism and Ethnicity, Annual Review of Sociology, Vol 19 (1993), 211-239.

Effendi,AM. Rasa Nasionalisme dan Tuntutan Global. Kompas, 28 April 1995.

Eriksen, T.H.(1993). Ethnicity and Nationalism Anthropological Perspectives. LondonBoulder, Colorado. Pluto Press.

Tatang Muttaqin,Dkk.,(2006), Membangun Nasionalisme Baru: Bingkai Ikatan Kebangsaan Indonesia Kontemporer, Diterbitkan Oleh: DirektoratKebudayaan, Pariwisata, Pemuda, Dan Olahraga Badan Perencanaan Pembangunan Nasional (Bappenas). Isbn 979-25-5820-9.

Chairul Anwar, (2014). Internalisasi Semangat Nasionalisme Melalui Pendekatan Habituasi (Perspektif Filsafat Pendidikan), Analisis: Jurnal Studi Keislaman, Volume 14, Nomor 1, Juni 2014.

Singgih Tri Sulistiyono, (2018). Nasionalisme, Negara-Bangsa, Dan Integrasi Nasional Indonesia: Masih Perlukah? Jurnal Sejarah Citra Lekha, Vol. 3, No. 1, 2018, Hlm. 3-12. Sollitan, R. W., Posumah, D., \& Rengkung, F. R. D. (2020). Potensi Perubahan Garis Batas Indonesia-Singapura (STudi Kasus Reklamasi di Pulau Nipah). JURNAL POLITICO, 9(1)

Sartono Kartodirdjo, (1999), Pengantar Sejarah Indonesia Baru: Sejarah Pergerakan Nasional dari Kolonialisme Sampai Nasionalisme, Jilid 2. Jakarta: Gramedia.

Umi Halwati, Imam Alfi, dkk 2018, Nasionalisme di Tengah Pluralitas dan Kebebasan Pers KOMUNIKA: Jurnal Dakwah dan Komunikasi Vol. 12, No. 2, Juli - Desember 2018. 